\title{
Teknologi Tepat Guna untuk Usaha Ikan Asin di Desa Kurban Bencana Rob
}

\author{
Appropriate Technology for Salted Fish Business in Rob's Sacrificial Village \\ Purnomo, Nurhayati \\ Universitas Muhammadiyah Semarang, Semarang \\ purnomo@unimus.ac.id, nurhayati@unimus.ac.id
}

Riwayat Artikel: Dikirim: 16 Oktober 2018; Diterima 29 November 2018; Diterbitkan 30 November 2018

\begin{abstract}
Abstrak
Usaha pengolahan ikan asin menjadi sangat penting bagi penduduk yang tinggal di daerah pinggir laut dan daerahnya menjadi kurban rob. Tambak yang sudah menyatu dengan laut akibat rob, menyebabkan pendapatan masyarakat menurun drastis. Hasil-hasil melaut dan tambak tidak dijual dalam keadaan mentah, namun ikan dan udang bisa diolah menjadi produk lain yang lebih menarik. Permasalahan yang dihadapi adalah kesulitan pengeringan ikan jika hujan, tingginya kadar minyak goring sehingga olahan makanan cepat tengik, dan makanan olahan cepat melempem. Kegiatan ini bertujuan untuk meningkatkan usaha pengolahan ikan asin di desa kurban rob sehingga menjadi mandiri secara ekonomi. Tujuan ini diraih melalui melalui peningkatan peralatan penunjang dan ketrampilan usaha. Alat pengering, peniris minyak, serta pengemas makanan diterapkan dalam kegiatan ini. Hasilnya menunjukkan bahwa dengan menggunakan alat pengering, pengeringan tidak lagi tergantung panas matahari. Kapasitas pengeringan meningkat $700 \%$ dari keadaan awal $1 \mathrm{~kg} /$ jam. Daya tahan gimbal meningkat menjadi 15 hari dari keadaan awal 4 hari. Begitu pula dengan daya tahan gimbal yang meningkat dari semula 7 hari menjadi 30 hari.
\end{abstract}

Kata kunci: Ikan asin, pengeringan, penirisan, kemasan.

\begin{abstract}
Salted fish processing business is very important for residents who live in coastal areas and the area becomes a victim of rob. Ponds that have been fused with the sea due to rob cause people's income drop dramatically. The results of fishing and ponds are not sold in raw conditions, but fish and shrimp can be processed into other products that are more attractive. The problem faced was the difficulty of drying fish if it rained, high levels of fried oil so that processed foods quickly rancid, and processed foods quickly sluggish. This activity aims to increase the salted fish processing business in the village of sacrifice rob so that it becomes economically independent. This goal is achieved through increasing the supporting equipment and business skills. Dryer, oil slicer, and food packaging are applied in this activity. The results show that by using a dryer, drying is no longer dependent on the sun's beat. Drying capacity increases by $700 \%$ from the initial state of $1 \mathrm{~kg} /$ hour. Dread resistance increases to 15 days from the initial 4 days. Similarly, dreadlocks endurance increased from 7 days to 30 days
\end{abstract}

Keywords: salted fish, drying, draining, packaging.

\section{PENDAHULUAN}

Air pasang laut (rob) telah merendam $3 / 4$ desa Surodadi Kecamatan Sayung Kabupaten Demak, Jawa Tengah. Seluruh $(100 \%)$ tambak yang ada menjadi tenggelam, dan menyatu, serta terhubung langsung dengan laut. Petani tambak tidak bisa lagi menghasilkan ikan bandeng dan udang yang sebelumnya merupakan hasil utama yang mempunyai harga jual yang tinggi. Saat ini, ikan bandeng dan udang sudah sangat sulit dibudidayakan di tambak. Ikan yang ada ditambak saat ini tergolong ikan liar yang masuk ke tambak karena terbawa air rob atau air pasang. Ikan-ikan liar inilah yang sekarang menghuni tambak. Harga jual ikan liar ini sangat rendah bahkan tidak laku di pasaran. 
Sehingga banyak petani tambak dan nelayan yang tidak mendapatkan penghasilan. Akibatnya penghasilan petani tambak pun tidak cukup untuk memenuhi kebutuhan hidup keluarga sehari-hari. Akibatnya tingkat kemiskinan di daerah ini meningkat.

Gambar 1:

Kondisi desa saat terjadi rob

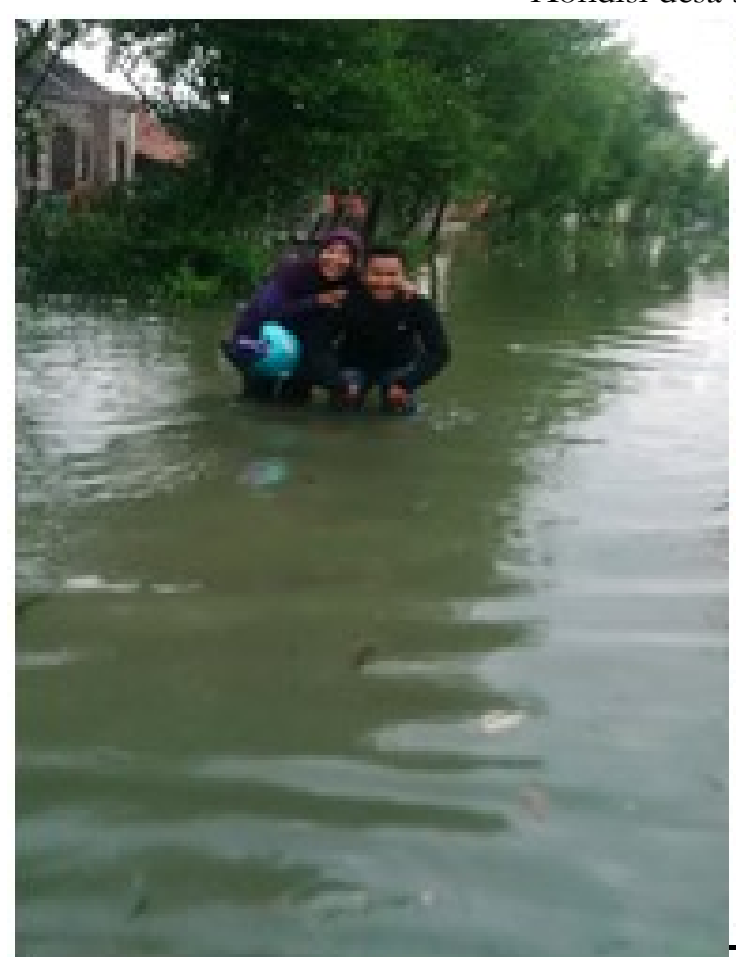

Sumber: Dokumentasi Pribadi

Untuk membantu memenuhi kebutuhan sehari-hari, ibu-ibu di desa Surodadi bekerja sebagai pengupas kulit udang, warung kecil- kecilan dan usaha mengolah hasil tambak/laut menjadi ikan asin. Usaha pengolahan ikan asin yang masih bertahan yaitu usaha ikan asin "GURIH' dan "BAROKAH". Usaha ikan asin "GURIH" dikelola oleh Ibu Sofiani yang tinggal di RT. 03 RW 01, sedangkan "BAROKAH" dikelola oleh Ibu Sa'adah yang tinggal di RT. 02 RW 01 Desa Surodadi Kecamatan Sayung Kabupaten Demak. Di tengah makin menurunnya kondisi perekonomian, kedua usaha ikan asin ini menjadi tumpuan ekonomi keluarga dan masyarakat sekitarnya yang ikut bekerja dan menggantungkan perekonomiannya pada kedua usaha ikan asin tersebut.

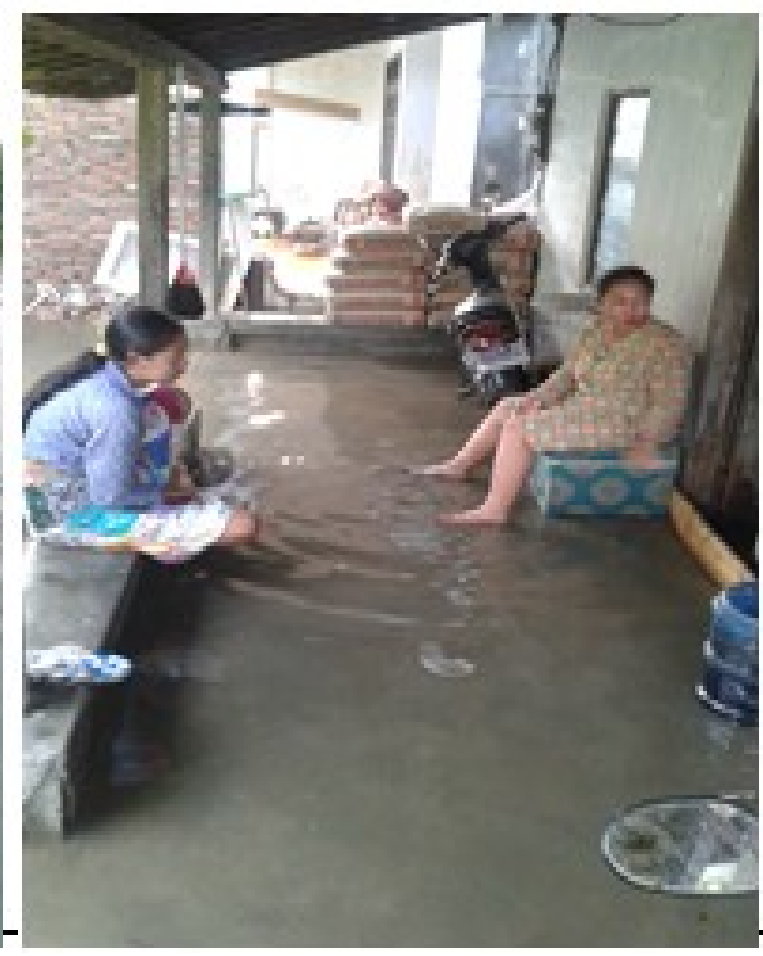

Permasalahan yang dialami kedua mitra adalah (1) pengeringan ikan asin sangat tergantung dari cuaca dan ikan asin sering bercampur debu halus karena pengeringan dilakukan di udara terbuka dan di pinggir jalan umum, (2) penyimpanan ikan asin sebelum kering tidak rapat akibatnya ikan asin cepat rusak dan berjamur, (3) pengemasan produk dilakukan dengan melipat ujung plastic kemudian diklip dengan staples sehingga tidak menarik dan udara masih bisa masuk dan mengoksidasi produk yang berupa gimbal dan ikan asin, (4) perlunya pembinaan dalam berwirausaha khususnya dalam optimalisasi potensi agar lebih produktif, dan (5) mitra belum mempunyai teknik pemasaran yang baik, pemasaran dilakukan dengan menjual langsung produk ikan asin ke 
konsumen/toko. Paper ini mengupas solusi hanya untuk permasalahan 1 sampai 3 saja, persoalan lainnya akan dibahas pada paper lainnya.

Tujuan kegiatan ini adalah (1) mengembangkan usaha ikan asin di dua usaha ikan asin di desa kurban rob sehingga keduanya dan orang yang bekerja padanya menjadi masyarakat yang mandiri secara ekonomi, (2) meningkatkan keterampilan berkreasi dan berinovasi, keterampilan menggunakan teknologi tepat guna dalam pengeringan, penyimpanan, pegemasan ikan asin, serta keterampilan dalam pemasaran produk ikan asin.

\section{METODE}

Metode yang diterapkan adalah (1) memperbaiki metode pengeringan dengan memanfaatkan mesin pengering jenis rak sehingga pengeringan ikan asin tidak di udara terbuka, tidak tergantung terik matahari, dan ikan asin tidak terkontaminasi dengan berbagai kotoran di udara, (2) mengembangkan fasilitas penyimpanan dan pengemasan produk ikan asin dengan menggunakan alat penyimpan dan mesin pengemas, (3) mitra diberikan bantuan alat pengemas produk ikan asin sehingga ikan asin awet tidak mudah terkena bakteri dan kotoran sehingga mudah rusak, dan (4) dibuatkan tempat plastik berlabel untuk mengemas ikan asin agar ikan asin menarik bagi konsumen.

\section{HASIL DAN PEMBAHASAN}

Alat pengering ikan yang dihasilkan disajikan dalam Gambar 2. Alat ini mempunyai kapasitas pengeringan 8 $\mathrm{kg} / \mathrm{jam}$ dan mampu mengeringkan ikan asin atau gimbal baik dalam suasana udara cerah maupun hujan. Keuntungan lain dari penggunaan pengering ini adalah terhindarnya ikan asin dari debu dan dari hinggapnya lalat yang merupakan penyebar bakteri/bibit penyakit.

Gambar 2:

Mesin pengering ikan asin yang dihasilkan

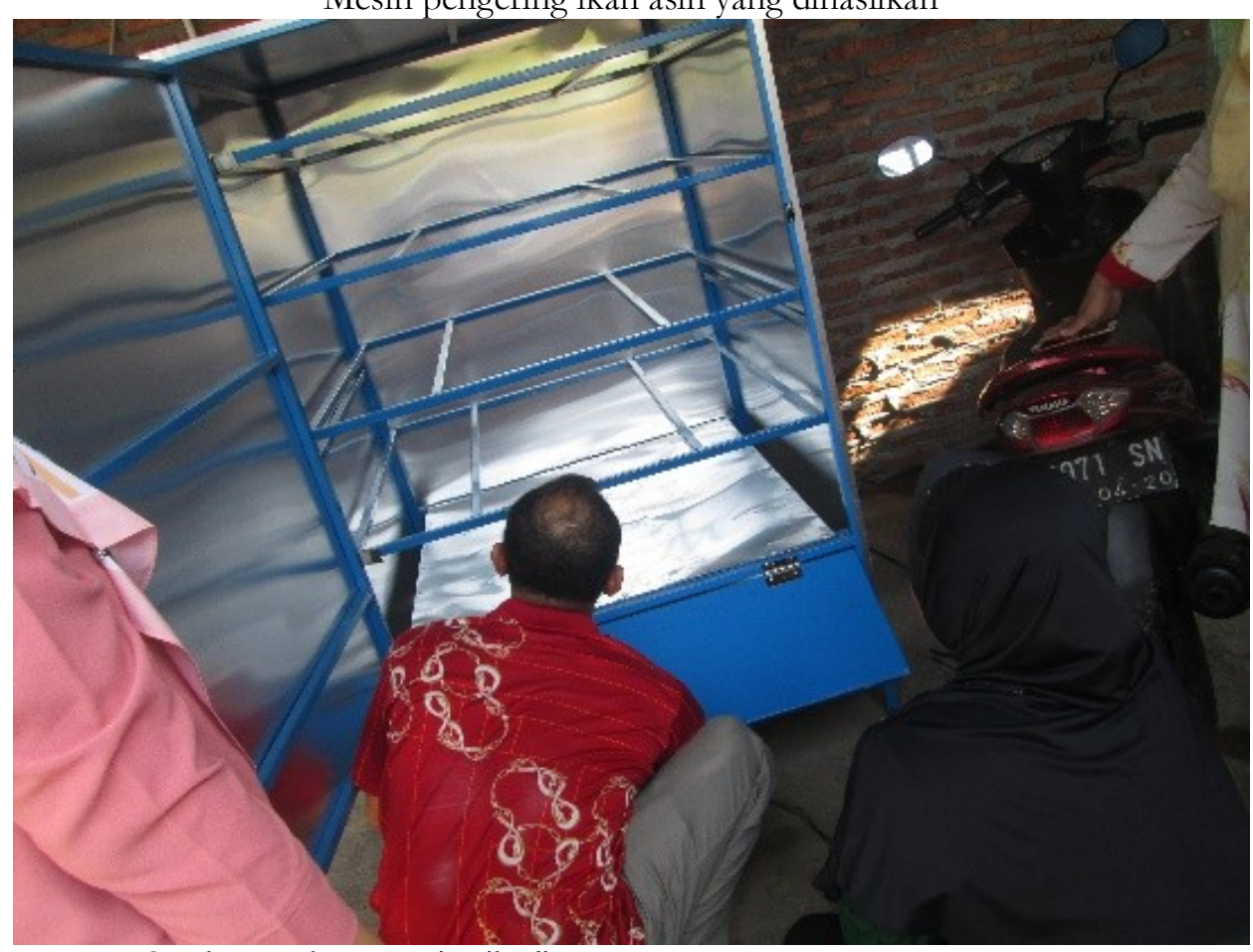

Sumber: Dokumentasi Pribadi 
Alat peniris yang dihasilkan sudah diimplementasikan untuk menghilangkan minyak yang terkandung dalam makanan. Para mitra juga sudah diberikan pelatihan penggunaan dan perawatan alat. Saat melakukan sosialisasikan penggunaan alat dan saat unjuk kerja alat, terlihat genangan minyak pada dasar box spinner setelah dilakukan proses penirisan 3 menit (lihat Gambar 3b). Terlihat pula bahwa gimbal terlihat lebih kering akibat makin sedikit kandungan minyaknya setelah ditiris.

Gambar 3:

Praktek penirisan minyak menggunakan mesin peniris (a), dan minyak yang keluar dari gimbal dan tertampung di alat peniris
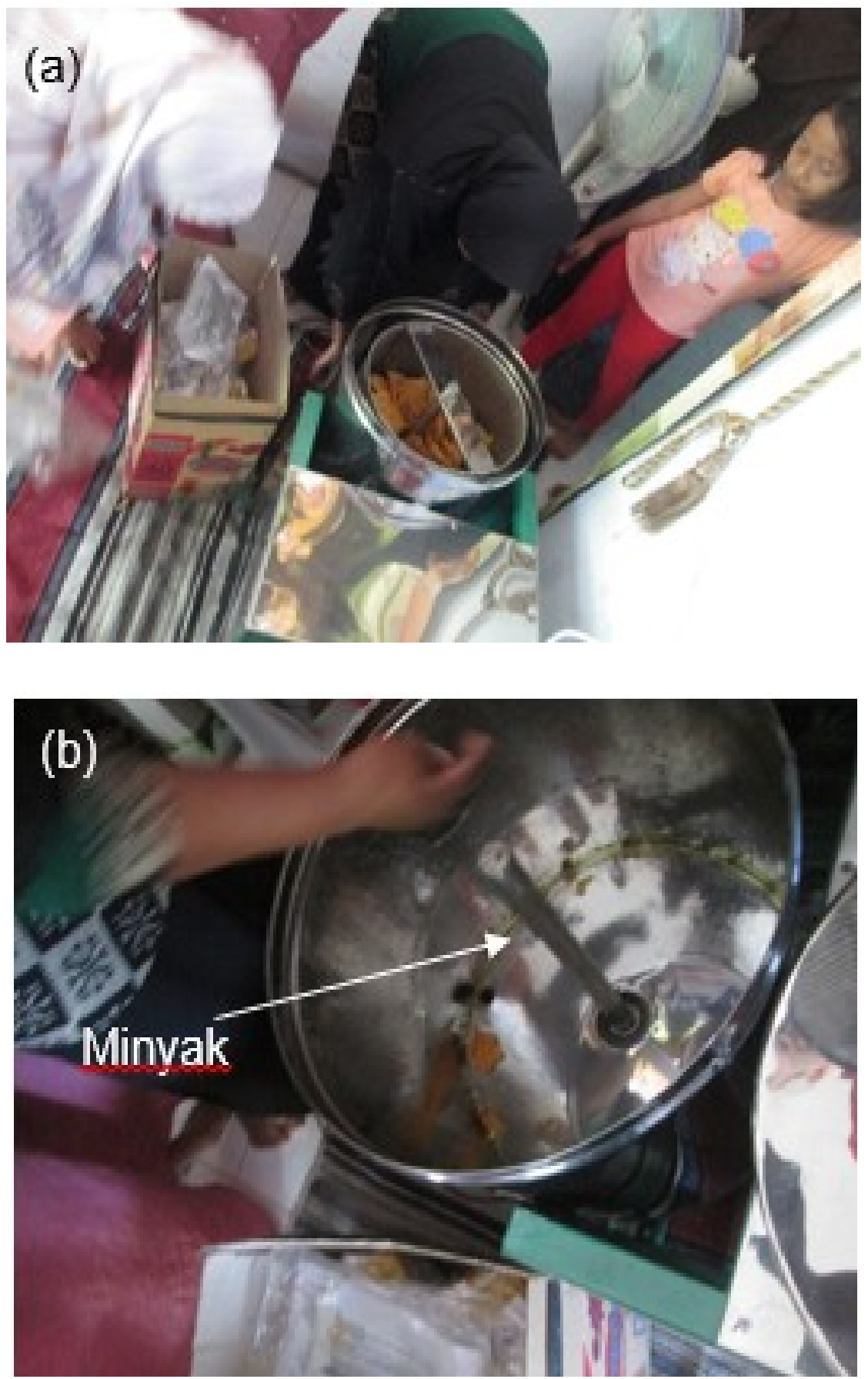

Sumber: Dokumentasi Pribadi 
Pengemasan telah dilakukan alat. Unjuk kerja alat diperagakan dan dengan menggunakan mesin pengemas menghasilkan kemasan produk yang lebih berupa hand sealer. Supaya lebih menarik, menarik sebagaimana diperlihatkan pada kemasan/bungkus dilengkapi dengan stiker (lihat Gambar 4). Terhadap pemilik usaha, telah dilakukan pula sosialisasi dan pelatihan penggunaan dan pemeliharaan Gambar 4(b). Disain sticker ada dua jenis, pertama dilekatkan pada sisi samping kemasan dan lainnya pada bagian atas kemasan.

Gambar 4:

Praktek penggunaan hand sealer dan pembuatan kemasan produk.
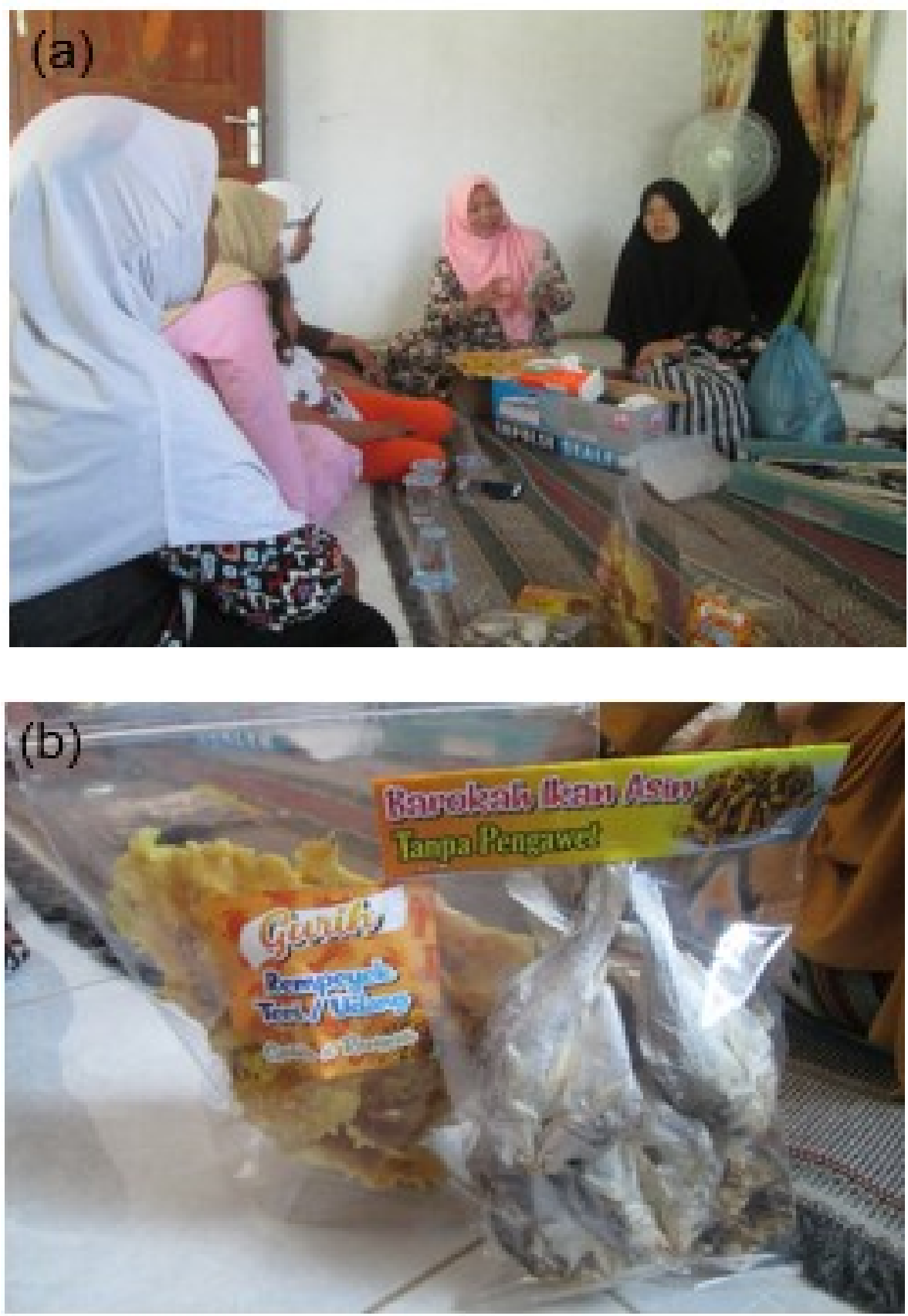

Sumber: Dokumentasi Pribadi 
Pelaksanaan kegiatan tidak berhenti saat pelatihan saja, tetapi implementasi setelah kegiatan juga dilakukan. Gambar 5 adalah hasil monitoring terhadap implementasi alat pengeringan, penirisan minyak, dan pengemasan menggunakan hand sealer.

Gambar 5:

Efek implementasi teknologi tepat guna.

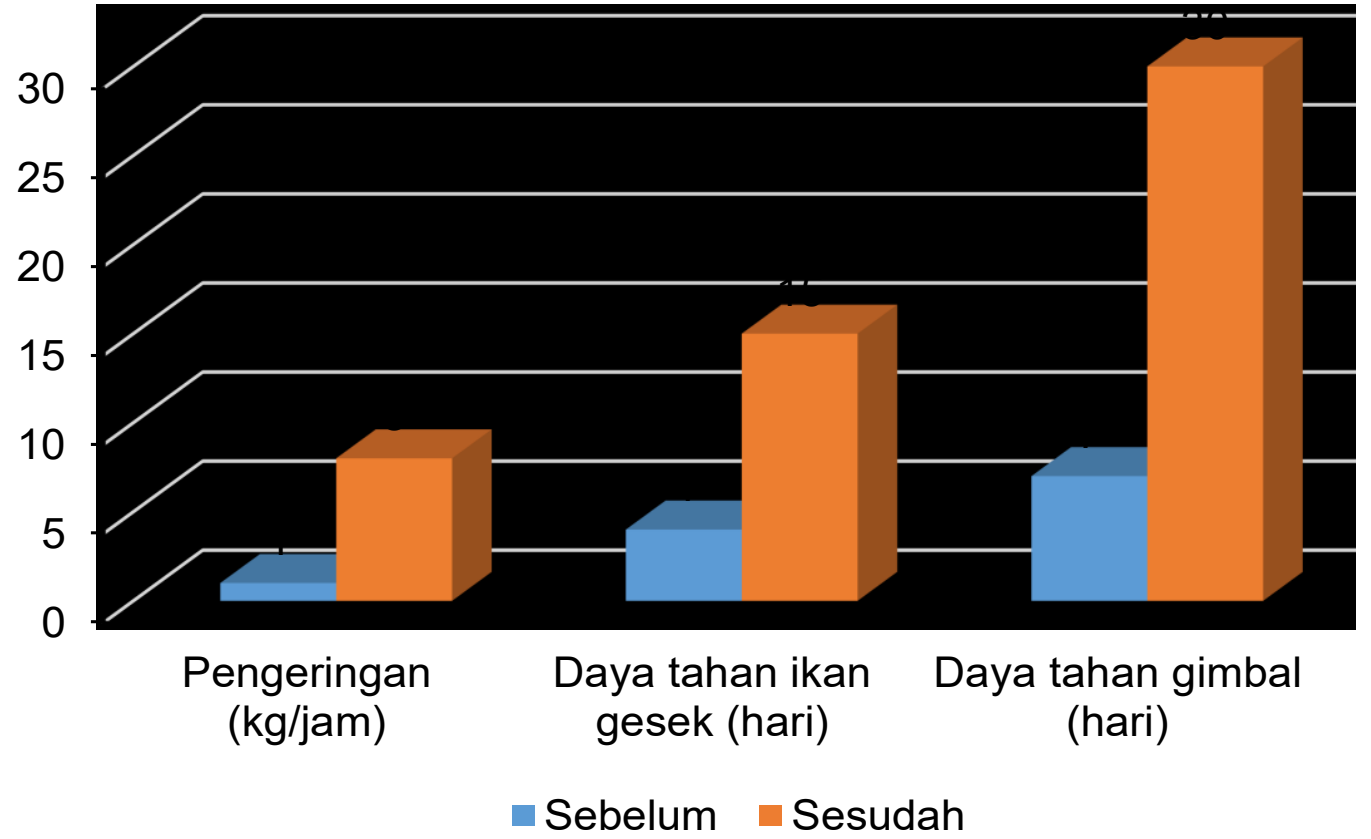

\section{KESIMPULAN}

Peralatan penunjang usaha dan ketrampilan pengusaha ikan asin telah berhasil ditingkatkan melalui kegiatan ini. Alat pengering, peniris minyak, serta pengemas makanan telah berhasil diterapkan dalam kegiatan ini. Penggunaan alat pengering memutus ketergantungan proses pengeringan terhadap panas matahari. Kapasitas pengeringan berhasil ditingkatkan $700 \%$, daya tahan gimbal meningkat $275 \%$, dan daya tahan gimbal yang meningkat $328 \%$ dari daya tahan awal yang hanya 7 hari.

\section{UCAPAN TERIMA KASIH}

Ucapan terima kasih kepada Direktorat Riset dan Pengabdian Masyarakat Direktorat Jenderal Penguatan Riset dan Pengembangan Kementerian Riset,
Teknologi, dan Pendidikan Tinggi Sesuai dengan Perjanjian Penugasan Pelaksanaan Program Pengabdian Masyarakat No.: 001/K6/KM/SP2H/PPM/2018, tanggal 19 Februari 2018 yang telah memfasilitasi pendanaan.

\section{DAFTAR PUSTAKA}

Bappeda Kabupaten Demak dan Biro Satatistik Kabupaten Demak, 2017

Biro Pusat Statistik. (2014). Jumlah Penduduk Miskin Indonesia Capai 28 Juta, diunduh 3 april 2016 dari http://www.beritasatu.com/nasional L193810-bps-maret-2014-jumlahpenduduk-miskin-indonesia-capai28-juta.html.

Walujodjati. A dan Darmanto. (2005). Rancang Bangun Mesin Pengering Ikan asin Untuk Industri Kecil Ikan asin, Momentum, Vol. 1, No. 1, April 2005: 27- 32 
Mesin Pengering cabinet dryer, diunduh 30

Mei 2017 dari

https://elsafta.wordpress.com/2010 L03/28/dryer/

Mesin pengemas (sealer), Diakses 7 Juni 2017 dari https://homeappliance.en.alibaba.co $\mathrm{m} /$ product/60351541541-

803380565/Fresh_world_vacuum_se aler_guangzhou_electronic.html. 